\title{
Doses e modos de aplicação de ureia revestida com polímero no cultivo de alface americana
}

\author{
Hamilton César de Oliveira CHARLO ${ }^{1 *}$, Juliano da Silva Martins de ALMEIDA², \\ Valdeci ORIOLI JÚNIOR ${ }^{1}$, Regina Maria Quintão LANA ${ }^{3}$
}

\begin{abstract}
${ }^{1}$ Instituto Federal de Educação, Ciência e Tecnologia do Triângulo Mineiro, Uberaba, MG, Brasil. (Orcid: *; 0000-0001-6202-7100)
${ }^{2}$ Escola Agrotécnica, Universidade Federal de Roraima, Boa Vista, RR, Brasil. (Orcid: 0000-0002-6661-0181)

${ }^{3}$ Instituto de Ciências Agrárias, Universidade Federal de Uberlândia, Uberlândia, MG, Brasil. (Orcid: 0000-0002-8860-6730)

*E-mail: hamiltoncharlo@iftm.edu.br (Orcid: 0000-0003-0663-2167)
\end{abstract}

Recebido em 18/06/2020; Aceito em 31/08/2020; Publicado em 08/09/2020.

\begin{abstract}
RESUMO: O objetivo deste estudo foi avaliar o efeito de doses e modos de aplicação de $\mathrm{N}$, fornecido por meio de ureia revestida, no estado nutricional e produção de alface americana. Utilizou-se o delineamento em blocos ao acaso em arranjo fatorial $6 x 4+1$, sendo seis doses de $\mathrm{N}(28,75 ; 57,50 ; 115,00 ; 172,50 ; 230,00 ; 287,50$ $\mathrm{kg} \mathrm{ha}^{-1}$ de N), como fonte a ureia revestida, e quatro modos de aplicação do nutriente (100\% da dose no transplante; $50 \%$ no transplante $+50 \%$ aos 10 dias após o transplante (DAT); $25 \%$ no transplante $+75 \%$ aos 10 dias DAT; $25 \%$ no transplante $+25 \%$ a cada cobertura, aos 10, 20 e 30 DAT). No tratamento adicional utilizou-se a ureia convencional. Foram determinados os teores foliares de N, P, K, Ca e Mg, a massa fresca total e comercial da cabeça, o diâmetro do caule, a altura da planta e o diâmetro da cabeça aos 30 e 60 dias após o transplante. Verificou-se que a adubação nitrogenada aumentou os teores foliares de $\mathrm{N}$, Ca e Mg, e reduziu os teores foliares de K e P. Não houve influência das doses de $\mathrm{N}$ proveniente de ureia revestida com polímero e dos modos de aplicação nos atributos morfológicos e produtivos da cultura.
\end{abstract}

Palavras-chave: Lactuca sativa L.; nitrogênio; fertilizante de liberação lenta; fertilizante de liberação controlada.

\section{Rates and applications ways of polymer-coated urea in crisphead lettuce cultivation}

\begin{abstract}
The aim of this study was to evaluate the effect of $\mathrm{N}$ rates (using a polymer-coated urea) and $\mathrm{N}$ application ways in nutritional status and yield of crisphead lettuce. The randomized block design in a $6 \times 4+$ 1 factorial arrangement was used, with six $\mathrm{N}$ rates $\left(28.75,57.50,115.00,172.50,230.00,287.50 \mathrm{~kg} \mathrm{ha}^{-1} \mathrm{of} \mathrm{N}\right)$, with the use of polymer-coated urea, and four nutrient application ways (100\% of the transplant rate, $50 \%$ at the transplant $+50 \%$ at the 10 days after the transplant (DAT), 25\% at the transplant $+75 \%$ at 10 days DAT, $25 \%$ at transplant $+25 \%$ at each side dressing fertilization at 10, 20 and $30 \mathrm{DAT}$ ). The additional treatment was related to the recommended $\mathrm{N}$ fertilization using conventional urea. $\mathrm{N}, \mathrm{P}, \mathrm{K}, \mathrm{Ca}$ and $\mathrm{Mg}$, total and commercial yield, stem diameter, plant height and head diameter were determined at 30 and 60 days after transplant. Nitrogen fertilization increased the $\mathrm{N}$, Ca and $\mathrm{Mg}$ foliar levels, independently of the application way. However, in general, it reduced the leaf levels of $\mathrm{K}$ and $\mathrm{P}$. There was no influence of $\mathrm{N}$ rates from polymercoated urea and application way on the morphological attributes and yield of the crop.
\end{abstract}

Keywords: Lactuca sativa L.; nitrogen; slow-release fertilizer; controlled-release fertilizer

\section{INTRODUÇÃO}

A alface (Lactuca sativa L.) é uma das hortaliças folhosas mais importantes no mundo. A produção mundial de alface em 2018 totalizou 27,3 milhões de toneladas, em uma área de 1,27 milhões de hectares (FAO, 2020). Estima-se que a produção de alface no Brasil, esteja em torno de 671.509 toneladas, sendo a $5^{\text {a }}$ hortaliça mais produzida (ANUÁRIO BRASILEIRO DE HORTI \& FRUTI, 2020). A alface também apresenta grande importância socioeconômica e nutricional na América do Sul (SILVEIRA et al., 2019), fazendo parte da dieta da maioria dos brasileiros (PEREIRA et al., 2020).

É uma cultura bastante exigente em $\mathrm{N}$, um nutriente que apresenta um comportamento complexo no sistema soloplanta-atmosfera (AWAAD et al., 2016; RESENDE et al.,
2012). Portanto, buscam-se formas para realização da adubação nitrogenada que sejam capazes de reduzir as perdas do elemento pelo ambiente de cultivo e, que aumentem a produtividade da cultura e rentabilidade.

Um dos modos de aplicação com potencial para reduzir os custos de produção é a aplicação de toda a dose de $\mathrm{N}$ no transplante das mudas de alface, por eliminar a necessidade de aplicações em cobertura. No entanto, principalmente em solos com baixo teor de argila, o $\mathrm{N}$ é facilmente perdido por lixiviação na forma de nitrato (COUTINHO NETO et al., 2014). Assim, o fornecimento completo do nutriente neste momento pode levar a uma baixa disponibilidade de $\mathrm{N}$, sobretudo na fase final do ciclo, período em que cultura apresenta a maior exigência do nutriente, ocasionando uma redução significativa no crescimento das plantas (ALMEIDA 
et al., 2011), bem como provocar o amarelecimento de folhas velhas e induzir a má formação da cabeça (GOTO et al., 2001), o que reduz a produtividade da cultura. O nitrogênio é constituinte de muitos componentes celulares vegetais, incluindo clorofila, aminoácidos e ácidos nucleicos. Por isso, a deficiência de nitrogênio rapidamente inibe o crescimento vegetal (TAIZ; ZEIGER, 2017).

A ureia tem sido o fertilizante nitrogenado mais utilizado na agricultura em função de sua alta concentração de $\mathrm{N}$ e de seu baixo custo por unidade do nutriente em comparação com outros fertilizantes. No entanto, esta fonte apresenta uma desvantagem em relação às demais, pois o $\mathrm{N}$ deste fertilizante pode ser perdido por volatilização na forma de $\mathrm{NH}_{3}$ quando não incorporado adequadamente ao solo (SILVA et al., 2012). Para reduzir ou eliminar estas desvantagens a ureia pode ser revestida com uma ou mais camadas de polímeros, as quais tem a finalidade de reduzir a velocidade de dissolução do fertilizante e, logo, a liberação do nutriente (PEDRINHO et al., 2015).

Em função disto, pesquisas vêm sendo desenvolvidas no campo de fertilizantes nitrogenados de liberação controlada (BALDANZA et al., 2018; CIVARDI et al., 2011). Essa nova tecnologia permite o fornecimento gradual de $\mathrm{N}$ às plantas, $\mathrm{O}$ que pode reduzir as perdas do nutriente por volatilização ou lixiviação, como também, reduzir a necessidade de várias aplicações em cobertura, portanto, diminuindo os custos de produção para o produtor (PETRIKOSKI et al., 2011; SANTOS et al., 2015; SILVA et al., 2020).

Frente à maior eficiência da ureia de liberação controlada no fornecimento de $\mathrm{N}$, a hipótese deste estudo é de que seja possível a utilização de doses menores em relação a fertilizantes não revestidos, e que a aplicação seja feita uma única vez. Diante do exposto, objetivou-se com esse trabalho avaliar o efeito de doses e modos de aplicação de $\mathrm{N}$, fornecido por meio de ureia revestida, no cultivo de alface americana.

\section{MATERIAL E MÉTODOS}

O experimento foi conduzido em condições de campo no município de Uberaba - MG, em área localizada a 19³9'81"' de latitude Sul e 47 57’72" de longitude Oeste. A precipitação e temperatura média do ar registrados durante a condução do experimento no campo (60 dias) estão expostos na Figura 1.

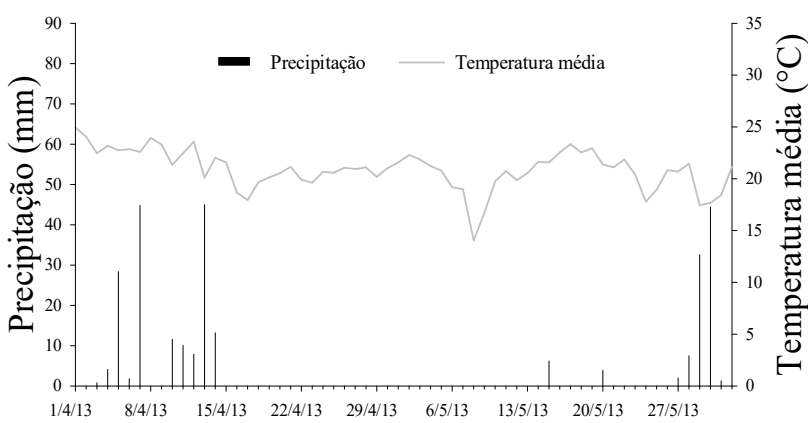

Figura 1. Dados diários de precipitação e temperatura média do ar durante o período experimental.

Figure 1. Daily data of precipitation and average air temperature during the experimental period.

A cultivar Lucy Brown pertence ao grupo de alface americana, e apresenta como características: coloração verde clara; ciclo de 85 a 90 dias, sendo de 45 a 55 dias após o transplante; e resistência ao Lettuce mosaic vírus: raça 1 . As mudas foram produzidas em bandejas multicelulares de 200 células $\left(12,5 \mathrm{~cm}^{3}\right)$, preenchidas com substrato comercial Bioplant ${ }^{\mathbb{B}}$. A irrigação por aspersão ocorreu diariamente de acordo com a necessidade da cultura.

Com base nos teores de $\mathrm{P}$ e $\mathrm{K}$ da análise do solo e as recomendações de Fontes (1999), em todos os tratamentos, a adubação básica no transplante constou da aplicação de 100 $\mathrm{kg} \mathrm{ha}{ }^{-1}$ de $\mathrm{P}_{2} \mathrm{O}_{5}$ e $90 \mathrm{~kg} \mathrm{ha}^{-1}$ de $\mathrm{K}_{2} \mathrm{O}$, tendo-se como fonte, respectivamente, o superfosfato simples e o cloreto de potássio.

O delineamento experimental utilizado foi em blocos casualizados em esquema fatorial $6 \times 4+1$, com quatro repetições. Os tratamentos consistiram da associação de seis doses de N (28,75; 57,50; 115,00; 172,50; 230,00 e 287,50 kg $\left.\mathrm{ha}^{-1}\right)$, tendo-se como fonte a ureia revestida com poliuretano ( $43 \%$ de N), e quatro modos de aplicação do nutriente $(100 \%$ da dose no transplante; $50 \%$ no transplante $+50 \%$ aos 10 dias após o transplante (DAT); 25\% no transplante $+75 \%$ aos 10 dias DAT; $25 \%$ no transplante $+25 \%$ a cada cobertura $(10,20$ e 30 DAT)). O tratamento adicional (tratamento controle) constou da aplicação de $30 \mathrm{~kg} \mathrm{ha}^{-1}$ de $\mathrm{N}$ no transplante $+30 \mathrm{~kg} \mathrm{ha}^{-1}$ de $\mathrm{N}$ aos $15 \mathrm{DAT}+45 \mathrm{~kg} \mathrm{ha}^{-1} \mathrm{de} \mathrm{N}$ aos $30 \mathrm{DAT}+45 \mathrm{~kg} \mathrm{ha}^{-1}$ de $\mathrm{N}$ aos 40 DAT (totalizando 150 $\mathrm{kg} \mathrm{ha}{ }^{-1}$ ), de acordo com Fontes (1999), tendo-se como fonte a ureia convencional. As doses de $\mathrm{N}$ foram estabelecidas com valores superiores e inferiores à dose recomendada por Fontes (1999) para a cultura da alface, que é de $150 \mathrm{~kg} \mathrm{ha}^{-1}$ de N.

As parcelas experimentais apresentavam $1,20 \mathrm{~m}$ de largura e 2,40 $\mathrm{m}$ de comprimento, totalizando uma área de $2,88 \mathrm{~m}^{2}$. Adotou-se o espaçamento de $0,30 \mathrm{~m}$ entre linhas e $0,30 \mathrm{~m}$ entre plantas. Cada parcela possuía quatro linhas, com um total de 32 plantas, considerando-se úteis as plantas das duas linhas centrais e descartando-se, nessas linhas, duas plantas no início e duas no final de cada linha.

$\mathrm{Na}$ fase de formação da cabeça (30 dias após transplante) coletaram-se, de 15 plantas por parcela, uma folha recémmadura, para avaliação do estado nutricional das plantas, conforme recomendado por Martinez et al. (1999). O material vegetal coletado foi lavado, acondicionado em sacos de papel perfurados e seco em estufa com circulação forçada de ar a $65{ }^{\circ} \mathrm{C}$ por 72 horas. Após a secagem o material foi moído em moinho tipo Willey para, então, ser utilizado nas determinações dos teores de N, P, K, Ca e Mg, conforme metodologia proposta por Embrapa (2009), sendo os teores foliares expressos em $\mathrm{g} \mathrm{kg}^{-1}$.

Aos 60 dias após o transplante foi realizada a colheita, quando então, com auxílio de régua e paquímetro, avaliaramse a altura e o diâmetro da cabeça; e o diâmetro do caule. Já a massa fresca total e comercial da cabeça foi obtida com balança digital.

Os dados obtidos foram submetidos à análise de variância pelo teste $\mathrm{F}$, quando constatada diferença significativa entre os tratamentos, efetuou-se a análise de regressão para as doses de $\mathrm{N}$ e teste Tukey de comparação de médias para os modos de aplicação. Valores de p <0,01 e 0,05 foram considerados significativos.

\section{RESULTADOS}

$\mathrm{Na}$ Tabela 1 encontram-se os resultados referentes aos teores foliares de N, P, K, Ca e Mg nas plantas de alface em função dos modos de fornecimento e doses de N. 
Tabela 1. Teores foliares de nitrogênio, fósforo, potássio, cálcio e magnésio em plantas de alface em função de doses e modos de aplicação de $\mathrm{N}$, tendo-se como fonte a ureia revestida.

Table 1. Leaf contents of nitrogen, phosphorus, potassium, calcium and magnesium in lettuce plants as a function of $\mathrm{N}$ doses and modes of application, using coated urea as a source.

\begin{tabular}{|c|c|c|c|c|c|}
\hline $\begin{array}{l}\text { Causa de } \\
\text { variação }\end{array}$ & $\mathrm{N}$ & $\mathrm{P}$ & $\begin{array}{c}\mathrm{K} \\
\mathrm{g} \mathrm{kg}^{-1}\end{array}$ & $\mathrm{Ca}$ & $\mathrm{Mg}$ \\
\hline \multicolumn{6}{|l|}{$\begin{array}{c}\text { Doses de N } \\
\left(\mathrm{kg} \mathrm{ha}^{-1}\right)\end{array}$} \\
\hline 28,75 & 22,60 & 2,34 & 34,75 & 6,11 & 1,80 \\
\hline 57,50 & 22,87 & 2,54 & 36,08 & 6,19 & 1,75 \\
\hline 115,00 & 23,16 & 2,21 & 32,62 & 6,86 & 1,75 \\
\hline 172,50 & 24,32 & 2,28 & 30,28 & 6,21 & 1,66 \\
\hline 230,00 & 24,70 & 2,47 & 30,28 & 6,95 & 1,76 \\
\hline 287,50 & 23,93 & 1,63 & 29,66 & 8,94 & 2,05 \\
\hline Teste F & $3,12^{*}$ & $8,23^{* *}$ & $7,13^{* *}$ & $22,52^{* *}$ & $5,04^{* *}$ \\
\hline Regressão & $\mathrm{L}^{* *}$ & $\mathrm{~L}^{* *} \mathrm{Q}^{* *}$ & $\mathrm{~L}^{* *}$ & $\mathrm{~L}^{* *} \mathrm{Q}^{* *}$ & $\mathrm{~L}^{*} \mathrm{Q}^{* *}$ \\
\hline \multicolumn{6}{|l|}{$\begin{array}{l}\text { Modos de } \\
\text { aplicação }\end{array}$} \\
\hline 1 & 23,19 & 2,30 & 31,81 & 6,72 & 1,77 \\
\hline 2 & 24,05 & 2,28 & 32,22 & 6,87 & 1,80 \\
\hline 3 & 23,54 & 2,25 & 33,25 & 6,90 & 1,86 \\
\hline 4 & 23,60 & 2,15 & 31,82 & 7,00 & 1,75 \\
\hline Teste F & $0,82^{\text {ns }}$ & $0,45^{\text {ns }}$ & $0,69^{\text {ns }}$ & $0,39^{\mathrm{ns}}$ & $0,85^{\text {ns }}$ \\
\hline DMS & 1,45 & 0,35 & 2,85 & 0,69 & 0,18 \\
\hline $\mathrm{N} \times \mathrm{MA}$ & $1,24^{\mathrm{ns}}$ & $2,59^{* *}$ & $2,12^{*}$ & $0,81^{\mathrm{ns}}$ & $2,22^{*}$ \\
\hline $\begin{array}{c}\text { Fatorial vs. } \\
\text { Adicional }\end{array}$ & $0,91^{\mathrm{ns}}$ & $14,30^{* *}$ & $0,14^{\mathrm{ns}}$ & $75,73^{* *}$ & $2,69^{\mathrm{ns}}$ \\
\hline $\begin{array}{c}\text { Média do } \\
\text { Fatorial }\end{array}$ & 23,60 & 2,24 & 32,54 & 6,87 & 1,80 \\
\hline $\begin{array}{l}\text { Média Trat. } \\
\text { Adicional }\end{array}$ & 22,66 & 1,37 & 31,82 & 10,90 & 2,00 \\
\hline Média Geral & 23,56 & 2,21 & 32,51 & 7,04 & 1,81 \\
\hline CV $(\%)$ & 8,13 & 20,60 & 11,53 & 12,86 & 13,22 \\
\hline \multicolumn{6}{|c|}{$\begin{array}{l}* \text { significativo a } 5 \% \text { de probabilidade, } * *=\text { significativo a } 1 \% \text { de } \\
\text { probabilidade, ns }=\text { não significativo pelo teste } \mathrm{F} \text {. ANOVA = análise de } \\
\text { variância, } \mathrm{L}=\mathrm{Linear}, \mathrm{Q}=\text { quadrático, DMS }=\text { diferença mínima } \\
\text { significativa, } \mathrm{T}=\text { transplante das mudas; } \mathrm{CV}=\text { coeficiente de variação, DAT } \\
=\text { dias após o transplante das mudas. MA }=\text { modo de aplicação, } 1=100 \% \\
\mathrm{~T}, 2=50 \% \mathrm{~T}+50 \% \text { aos } 10 \mathrm{DAT}, 3=25 \% \mathrm{~T}+75 \% \text { aos } 10 \mathrm{DAT}, 4= \\
25 \% \mathrm{~T}+25 \% \text { a cada } 10 \mathrm{DAT} \text {. }\end{array}$} \\
\hline
\end{tabular}

Verifica-se que, embora os modos de aplicação não tenham influenciado de forma significativa os teores foliares de N (Tabela 1), o incremento das doses propiciou aumento proporcional e significativo no teor do nutriente nas folhas das plantas de alface (Tabela 1, Figura 2). Verificou-se, ainda, que a aplicação de $\mathrm{N}$ por meio de ureia convencional de acordo com as recomendações oficiais do Estado de Minas Gerais, propiciou teores semelhantes àqueles obtidos com aplicação de ureia revestida (Tabela 1). Quanto aos teores foliares de K, na Tabela 1 e Figura 3, é possível observar que as doses de $\mathrm{N}$ influenciaram significativamente esta variável, sendo o efeito observado dependente do modo de aplicação adotado na adubação nitrogenada. Nota-se que ao se aumentar a dose de $\mathrm{N}$ houve redução linear nos teores de $\mathrm{K}$ nas folhas de alface para a maioria dos modos de aplicação do fertilizante nitrogenado. No entanto, ao se aplicar 25\% da dose de $\mathrm{N}$ no transplante e o restante $(75 \%)$ aos 10 dias após o transplante (DAT), o teor de $\mathrm{K}$ manteve-se constante, independentemente da dose de N. O tratamento adicional, onde se utilizou ureia convencional, não propiciou diferença significativa no teor de $\mathrm{K}$ foliar em relação àqueles obtidos com o uso do fertilizante polimerizado (Tabela 1).

A interação entre doses de $\mathrm{N}$ e modos de aplicação do nutriente também foi significativa para o teor foliar de $\mathrm{P}$
(Tabela 1). Verifica-se na Figura 4 que, ao se fornecer o $\mathrm{N}$ todo no transplante ou $25 \%$ da dose no transplante e $25 \%$ a cada 10 DAT, houve uma redução linear do teor de $\mathrm{P}$ nas folhas de alface à medida que se aumentou o fornecimento do nutriente. No entanto, para os demais modos de aplicação a redução do teor de $\mathrm{P}$ foi observada apenas para as três doses superiores de N (Figura 4). Ainda, ao se aplicar N por meio de ureia revestida, observou-se teor foliar de $\mathrm{P}$ significativamente superior ao tratamento com aplicação de ureia convencional (Tabela 1 ).

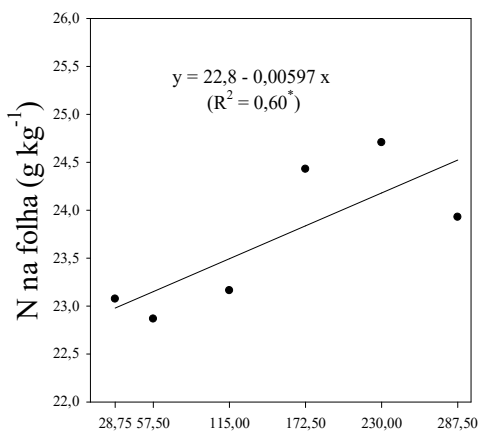

Dose de N $\left(\mathrm{kg} \mathrm{ha}^{-1}\right)$

Figura 2. Teor foliar de nitrogênio em função de doses de nitrogênio, fornecidas por meio de ureia revestida, em alface americana.

Figure 2. Leaf nitrogen content as a function of nitrogen doses, supplied by coated urea, in American lettuce.

A concentração de Ca no tecido foliar foi significativamente influenciada pelas doses de $\mathrm{N}$, independentemente do modo de aplicação do nutriente (Tabela 1). Na Figura 5 é possível observar que ao se aumentar o fornecimento de $\mathrm{N}$ houve um incremento linear no teor foliar de Ca.

Quanto aos teores foliares de $\mathrm{Mg}$, verifica-se na Tabela 1 e Figura 6 que houve influência significativa das doses de $\mathrm{N}$ somente em dois modos de aplicação do nutriente. Na Figura 6 é possível notar que, ao se aplicar toda a dose de $\mathrm{N}$ transplante das mudas, os teores de $\mathrm{Mg}$ diminuíram até a dose (estimada) de $146 \mathrm{~kg} \mathrm{ha}^{-1}$ de N. A aplicação de doses superiores a esta levaram a um incremento no teor foliar de $\mathrm{Mg}$. Já, ao se fornecer $25 \%$ da dose de $\mathrm{N}$ no transplante e o restante aos $10 \mathrm{DAT}$, verificou-se um aumento linear no teor do nutriente à medida que se forneceu mais $\mathrm{N}$.

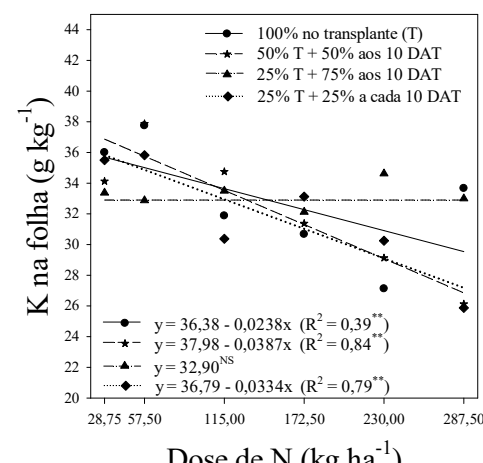

Figura 3. Teor foliar de potássio em função de doses de nitrogênio, fornecidas por meio de ureia revestida, em alface americana.

Figure 3. Leaf potassium content as a function of nitrogen doses, provided by coated urea, in American lettuce. 


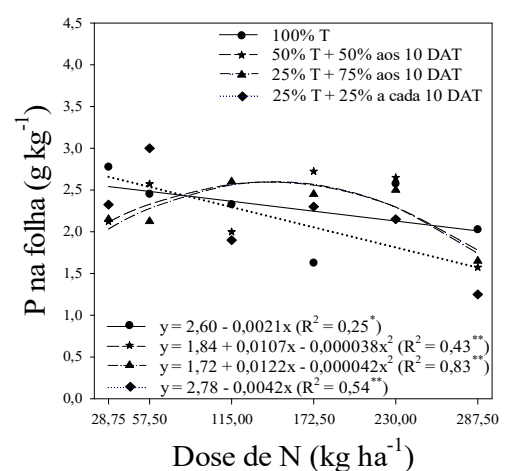

Figura 4. Teor foliar de fósforo em função de doses de nitrogênio, fornecidas por meio de ureia revestida, em alface americana. Figure 4. Leaf content of phosphorus as a function of nitrogen doses, supplied by means of coated urea, in American lettuce.

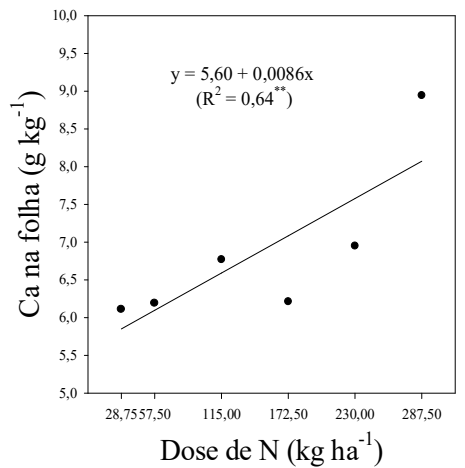

Figura 5. Teor foliar de cálcio em função de doses de nitrogênio, fornecidas por meio de ureia revestida, em alface americana.

Figure 5. Leaf calcium content as a function of nitrogen doses, supplied by coated urea, in American lettuce.

$\mathrm{Na}$ Tabela 2 pode-se observar que não houve diferenças significativas nos atributos produtivos e morfológicos das plantas de alface em função do fornecimento de $\mathrm{N}$ e do modo de aplicação do nutriente. Quanto à massa fresca total e comercial da cabeça, os valores médios obtidos foram, respectivamente, 210,4 e 183,7g planta $^{-1}$ (Tabela 2). O diâmetro médio do caule e da cabeça aos 60 dias após o transplante foram 2,12 e 17,78 cm, respectivamente (Tabela 2). Para a altura da cabeça observou-se valor médio de 11,30 cm (Tabela 2), sendo estes valores condizentes aos verificados em plantas de alface americana em cultivos comerciais.

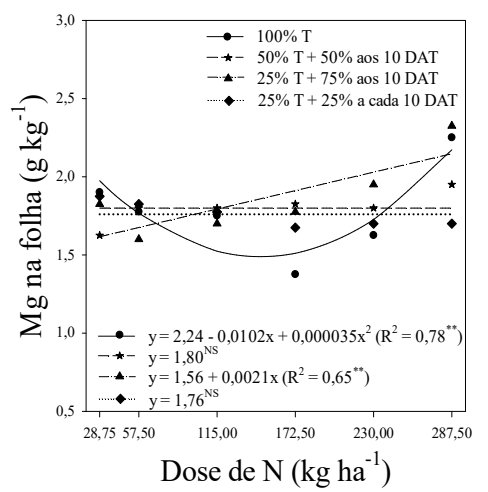

Figura 6. Teor foliar de magnésio em função de doses de nitrogênio, fornecidas por meio de ureia revestida, em alface americana.

Figure 6. Leaf magnesium content as a function of nitrogen doses, supplied by means of coated urea, in American lettuce.
Tabela 2. Massa fresca (MF) e comercial (MC) da cabeça, diâmetro do caule (dC) e da cabeça (DC), e altura da planta (H) aos 60 dias após o transplante de plantas de alface americana em função de doses e modos de aplicação de $\mathrm{N}$, tendo-se como fonte a ureia revestida.

Table 2. Fresh (MF) and commercial (MC) mass of the head, stem diameter (AD) and head (DC), and plant height (H) at 60 days after transplanting American lettuce plants according to doses and modes of application of $\mathrm{N}$, using coated urea as a source.

\begin{tabular}{|c|c|c|c|c|c|}
\hline \multirow{2}{*}{$\begin{array}{c}\text { Causa } \\
\text { de variação }\end{array}$} & $\mathrm{MF}$ & $\mathrm{MC}$ & $\mathrm{dC}$ & DC & $\mathrm{H}$ \\
\hline & \multicolumn{2}{|c|}{--- g planta ${ }^{-1}$--- } & \multicolumn{3}{|c|}{ 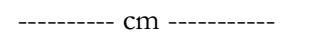 } \\
\hline $\begin{array}{c}\text { Doses de N } \\
\left(\mathrm{kg} \mathrm{ha}^{-1}\right)\end{array}$ & & & & & \\
\hline 28,75 & 203,1 & 180,4 & 2,1 & 17,5 & 11,1 \\
\hline 57,50 & 199,5 & 177,9 & 2,0 & 17,3 & 10,8 \\
\hline 115,00 & 217,2 & 188,2 & 2,1 & 17,7 & 11,6 \\
\hline 172,50 & 227,5 & 201,2 & 2,1 & 17,9 & 11,9 \\
\hline 230,00 & 217,9 & 192,5 & 2,2 & 17,7 & 10,9 \\
\hline 287,50 & 196,2 & 174,3 & 2,2 & 18,6 & 11,5 \\
\hline Teste F & $0,56^{\mathrm{ns}}$ & $0,42^{\text {ns }}$ & $1,61^{\mathrm{ns}}$ & $0,75^{\mathrm{ns}}$ & $1,71^{\mathrm{ns}}$ \\
\hline Regressão & - & - & $\mathrm{L}^{* *}$ & - & - \\
\hline $\begin{array}{l}\text { Modos de } \\
\text { aplicação }\end{array}$ & & & & & \\
\hline 1 & 214,6 & 187,0 & 2,04 & 17,7 & 11,0 \\
\hline 2 & 191,7 & 169,9 & 2,16 & 17,7 & 11,5 \\
\hline 3 & 229,9 & 205,5 & 2,13 & 18,3 & 11,5 \\
\hline 4 & 205,0 & 180,6 & 2,15 & 17,4 & 11,2 \\
\hline Teste F & $1,40^{\text {ns }}$ & $1,25^{\mathrm{ns}}$ & $1,39^{\mathrm{ns}}$ & $0,69^{\mathrm{ns}}$ & $0,73^{\text {ns }}$ \\
\hline DMS & 50,46 & 51,12 & 0,18 & 1,62 & 1,00 \\
\hline $\mathrm{N} x \mathrm{MA}$ & $0,78^{\text {ns }}$ & $0,46^{\mathrm{ns}}$ & $0,96^{\text {ns }}$ & $0,81^{\mathrm{ns}}$ & $0,60^{\mathrm{ns}}$ \\
\hline $\begin{array}{l}\text { Fatorial vs. } \\
\text { Adicional }\end{array}$ & $0,01^{\mathrm{ns}}$ & $0,02^{\mathrm{ns}}$ & $0,15^{\text {ns }}$ & $0,03^{\mathrm{ns}}$ & $0,06^{\mathrm{ns}}$ \\
\hline $\begin{array}{l}\text { Média do } \\
\text { Fatorial }\end{array}$ & 210,3 & 183,5 & 2,1 & 17,8 & 11,3 \\
\hline $\begin{array}{l}\text { Média Trat. } \\
\text { Adicional }\end{array}$ & 212,3 & 188,2 & 2,2 & 18,0 & 11,1 \\
\hline Média Geral & 210,4 & 183,7 & 2,1 & 17,8 & 11,3 \\
\hline $\mathrm{CV}(\%)$ & 31,6 & 36,7 & 10,9 & 12,0 & 11,7 \\
\hline
\end{tabular}

** = significativo a $1 \%$ de probabilidade, $\mathrm{ns}=$ não significativo pelo teste $\mathrm{F}$. ANOVA $=$ análise de variância, $\mathrm{L}=$ Linear, $\mathrm{DMS}=$ diferença mínima significativa, $\mathrm{T}=$ transplante das mudas; $\mathrm{CV}=$ coeficiente de variação, $\mathrm{DAT}$ $=$ dias após o transplante das mudas. MA $=$ modo de aplicação, $1=100 \%$ $\mathrm{T}, 2=50 \% \mathrm{~T}+50 \%$ aos $10 \mathrm{DAT}, 3=25 \% \mathrm{~T}+75 \%$ aos $10 \mathrm{DAT}, 4=$ $25 \% \mathrm{~T}+25 \%$ a cada $10 \mathrm{DAT}$.

\section{DISCUSSÃO}

As concentrações de $\mathrm{N}$ foliar observadas neste estudo $\left(23,07\right.$ a 24,70 $\mathrm{g} \mathrm{kg}^{-1}$, Figura 2) são inferiores àquelas consideradas adequadas na nutrição da cultura da alface por Matinez et al. (1999) e Trani; Raij (1996), ou seja, $40 \mathrm{~g} \mathrm{~kg}^{-1} \mathrm{e}$ de 30 a $50 \mathrm{~g} \mathrm{~kg}^{-1}$, respectivamente. Todavia, relatos de teores abaixo daqueles tidos como referência mesmo com produtividade adequada são, relativamente, frequentes. Oliveira et al. (2010), por exemplo, ao analisarem amostras foliares de alface (cv. Regina 2000) em cultivo orgânico, encontraram valores entre 27,6 a 29,3 $\mathrm{g} \mathrm{kg}^{-1} \mathrm{~N}$. Por sua vez, Resende et al. (2012) avaliaram os efeitos de diferentes doses de $\mathrm{N}$ e Mo em alface americana (cv. Raider) e observaram que o teor máximo de $\mathrm{N}$ nas folhas foi de $32,6 \mathrm{~g} \mathrm{~kg}^{-1}$. Ressalta-se que neste experimento não foram notados sintomas visuais de deficiência de $\mathrm{N}$, independentemente da dose e do modo de aplicação do nutriente.

Os teores foliares de $\mathrm{K}$ variaram entre 29,66 a 36,08

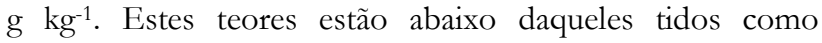
adequados em planta de alface por Trani; Raij (1996) [50 a 80 $\mathrm{g} \mathrm{kg}^{-1}$ de K] e Martinez et al. (1999) [70 $\mathrm{g} \mathrm{kg}^{-1}$ de K]. No 
entanto, são próximos aos obtidos por Mógor; Câmara (2009) que, ao avaliarem o estado nutricional da cultura sob sistema orgânico de produção, verificaram teores foliares de 17,8 a $35,5 \mathrm{~g} \mathrm{~kg}^{-1}$ de $\mathrm{K}$.

Segundo Trani; Raij (1996) a concentração de cálcio nas folhas de plantas adequadamente nutridas varia de 15 a $25 \mathrm{~g}$ $\mathrm{kg}^{-1}$. Neste trabalho a maior dose de $\mathrm{N}\left(287,50 \mathrm{~kg} \mathrm{ha}^{-1}\right.$ de N) propiciou $8,94 \mathrm{~g} \mathrm{~kg}^{-1}$ de $\mathrm{Ca}$ nas folhas de alface. O teor encontrado representa $77,46 \%$ do recomendado por Martinez et al. (1999) [11,54 $\mathrm{g} \mathrm{kg}^{-1}$ de Ca]. Resende et al. (2012) obtiveram valores inferiores aos observados neste experimento, os quais variaram de 6,60 a $5,50 \mathrm{~g} \mathrm{~kg}^{-1}$ na cultivar Raider.

O maior teor observado foi de 2,05 $\mathrm{g} \mathrm{kg}^{-1}$ de $\mathrm{Mg}$. Este valor encontra-se abaixo do considerado adequado por Trani; Raij (1996) [4,0 a 6,0 $\mathrm{g} \mathrm{kg}^{-1} \mathrm{de} \mathrm{Mg}$ e Martinez et al. (1999) [4 $\mathrm{g} \mathrm{kg}^{-1} \mathrm{de} \mathrm{Mg}$, o que se deve ao baixo teor inicial de $\mathrm{Mg}$ no solo.

Embora se tenha, inicialmente, o $\mathrm{N}$ principalmente em formas amoniacais ao se aplicar ureia ao solo, o processo de nitrificação, que ocorre de forma intensa em solos bem drenados, proporciona aumento na concentração de nitrato no solo no decorrer do tempo. Assim, os incrementos nos teores foliares de $\mathrm{Ca}$ e $\mathrm{Mg}$ em função do fornecimento de $\mathrm{N}$ pode estar relacionado à necessidade das plantas em aumentarem a absorção de cátions ao absorverem mais $\mathrm{N}$ na forma de nitrato para a manutenção do balanço interno de cátions-ânions (MENGEL; KIRKBY, 2001).

A ausência de efeitos significativos nos atributos morfológicos e produtivos da cultura em função das doses de $\mathrm{N}$ pode estar relacionada ao histórico da área de cultivo, haja vista que se trata de uma área onde o uso de composto orgânico é frequente e que uma quantidade significativa de restos vegetais foi incorporada ao solo alguns dias antes do transplante das mudas. Assim, a mineralização destes materiais orgânicos, e consequente disponibilização de $\mathrm{N}$, associada à menor dose de $\mathrm{N}\left(28,75 \mathrm{~kg} \mathrm{ha}^{-1}\right)$ podem ter suprido a necessidade da cultura neste nutriente para as condições de cultivo adotadas neste experimento.

Embora não se tenham verificado efeitos dos tratamentos, de forma geral, os valores dos atributos produtivos ficaram dentro dos relatados na literatura, visto que Valeriano et al. (2018) observaram em alface americana, na mesma região de cultivo, massa fresca total e comercial de, respectivamente, 330 e 130,29 g planta $^{-1}$. Quanto ao diâmetro do caule, os valores são semelhantes aos obtidos por Santana et al. (2012) que, em vários cultivares de alface americana, verificaram diâmetro de caule médio de $2,39 \mathrm{~cm}$.

No tocante aos modos de aplicação de N, a ausência de efeitos significativos nos atributos morfológicos e produtivos das plantas de alface, provavelmente, decorre da pequena perda de $\mathrm{N}$ no solo, mesmo ao se aplicar toda a dose do nutriente no transplante das mudas. É importante ressaltar que a ocorrência e intensidade de chuvas foram pequenas durante o período experimental (Figura 1) e que a cultura da alface possui um ciclo muito curto, o que acaba por reduzir as perdas de $\mathrm{N}$ por lixiviação. Considerando que se realizou a irrigação durante o período experimental, a lixiviação seria o principal processo de perda de $\mathrm{N}$.

Chama a atenção o fato de aplicações tardias de um adubo de liberação lenta não ter ocasionado assincronia entre a exigência nutricional da cultura e a liberação de $\mathrm{N}$ pelo fertilizante. Isto pode estar relacionado à rápida dissolução e liberação de $\mathrm{N}$ da ureia revestida utilizada no estudo. Civardi et al. (2011), estudando a eficiência agronômica da ureia revestida com o polímero considerado neste estudo para a cultura do milho, não verificaram benefício técnico e econômico ao se optar por este tipo de fertilizante. Assim, de forma semelhante, no presente estudo o polímero utilizado no revestimento da ureia pode não ter garantido uma liberação lenta e gradual do N.

A liberação não gradual ou irregular de ureia revestida com polímeros é relatada na literatura em função da temperatura do ambiente (Adams et al., 2013). Independentemente do material de revestimento do fertilizante, a temperatura de $30{ }^{\circ} \mathrm{C}$ aumenta liberação de nutrientes pela diminuição da viscosidade do material de revestimento (Sarkar et al., 2020); tornando assim a liberação mais rápida, e, desta forma, não são obtidos os efeitos positivos de liberação gradual do nitrogênio, uma vez que pode haver assincronia com as exigências da cultura. No presente estudo as temperaturas médias (Figura 1), especialmente no início do experimento ficaram próximas a $30^{\circ} \mathrm{C}$, podendo-se inferir que durante o dia as temperaturas foram superiores a $30{ }^{\circ} \mathrm{C}$, promovendo assim a liberação acelerada do nitrogênio e, consequentemente, ausência de benefícios do revestimento da ureia.

\section{CONCLUSÕES}

A adubação nitrogenada aumentou os teores foliares de $\mathrm{N}$ e Ca, independentemente do modo de aplicação utilizado. No entanto, reduziu os teores foliares de K e P. Não houve influência das doses e dos modos de aplicação de $\mathrm{N}$ revestido nos atributos morfológicos e produtivos da cultura da alface (cv. Lucy Brown).

\section{REFERÊNCIAS}

ADAMS, C.; FRANTZ, J.; BUGBEE, B. Macro and micronutrient-release characteristics of three polymercoated fertilizers: theory and measurements. Journal of Plant Nutrition and Soil Science, Landau, v. 176, n. 1, p. 76-88. 2013. https://doi.org/10.1002/jpln.201200156 ANUÁRIO BRASILEIRO DE HORTI \& FRUTI. 2020. Disponível http://www.editoragazeta.com.br/itewp/wpcontent/uploads/2020/05/HORTIFRUTI_2020.pdf. Acesso em: 25 de mai. 2020.

ALMEIDA, T. B. F.; PRADO, R. M.; CORREIA, M. A. R.; PUGA, A. P.; BARBOSA, J. C. Avaliação nutricional da alface cultivada em soluções nutritivas suprimidas de macronutrientes. Biotemas, Florianópolis, v. 24, n. 2, p. 27-36. 2011. DOI: https://doi.org/10.5007/21757925.2011v24n2p27

AWAAD, M. S.; BADR, R. A.; BADR, M. A.; ABDELRAHMAN, A. H. Effects of different nitrogen and potassium sources on lettuce (Lactuca sativa L.) yield in a sandy soil. Eurasian Journal of Soil Science, Samsun, v. 5 , n. 4, p. 299-306, 2016. DOI: 10.18393/ejss.2016.4.299-306

BALDANZA, V. A. R.; SOUZA JÚNIOR, F. G.; FILHO, S. T., FRANCO, H. A.; OLIVEIRA, G. E.; CAETANO, R. M. J.; HERNANDEZ, J. A. R.; FERREIRA LEITE, S. G.; FURTADO SOUSA, A. M.; NAZARETH SILVA, A. L. Controlled-release fertilizer based on poly(butylene succinate)/urea/clay and its effect on lettuce growth. 
Journal of Applied Polymer Science, v. 135, n. 47, e46858, 2018.2 DOI: https://doi.org/10.1002/app.46858

CIVARDI, E. A.; SILVEIRA NETO, A. N.; RAGAGNIN, V. A.; GODOY, E. R.; BROD, E. Ureia de liberação lenta aplicada superficialmente e ureia comum incorporada ao solo no rendimento do milho. Pesquisa Agropecuária Tropical, Goiânia, v. 41, n. 1, p. 52-59, 2011. DOI: https://doi.org/10.5216/pat.v41i1.8146

COUTINHO NETO, A. M.; COUTINHO, E. L. M.; ORIOLI JÚNIOR, V.; CORÁ, J. E.; SILVA, A. R. B.; SCATOLIN, M. Nitrogen fertilization management in no-tillage maize with different winter crops. Bioscience Journal, Uberlândia, v. 29, n. 6, p. 1981-1988, 2014.

EMBRAPA - Empresa Brasileira de Pesquisa Agropecuária. Manual de métodos de análises químicas de solos, plantas e fertilizantes. Centro Nacional de Pesquisa de Solos. Brasília: Embrapa, 2009. 627 p.

FAO - FOOD AND AGRICULTURAL ORGANIZATION - FAO. FAO Statistical Yearbook. New York, 2020. Disponível em:< http://www.fao.org/faostat/en/\#home>. Acesso em: 25 jul. 2020.

FONTES, P. C. R. Alface. In: RIBEIRO, A. C.; GUIMARÃES, P. T. G.; ALVAREZ V.; V. H. Recomendações para o uso de corretivos e fertilizantes em Minas Gerais: $5^{\text {a }}$ Aproximação. Viçosa: Comissão de Fertilidade do Solo do Estado de Minas Gerais, 1999. p. 177.

GOTO, R.; GUIMARÃES, V. F.; ECHER, M. M. Aspectos fisiológicos e nutricionais no crescimento e desenvolvimento de plantas hortícolas. In: FOLEGATTI, M. V.; CASARINI E.; BLANCO, F. F.; BRASIL, R. P. C.; RESENDE, R. S. Fertirrigação: flores, frutas e hortaliças. Guaíba: Agropecuária, 2001. p. 241-268.

MARTINEZ, H. E. P.; CARVALHO, J. G. C.; SOUZA, R. B. Diagnose foliar. In: RIBEIRO, A. C.; GUIMARÃES, P. T. G.; ALVAREZ V.; V. H. Recomendações para o Uso de Corretivos e Fertilizantes em Minas Gerais: $5^{\circ}$ Aproximação. Viçosa: Comissão de Fertilidade do Solo do Estado de Minas Gerais, 1999. p.143-167.

MENGEL, K.; KIRKBY, E. A. Principles of plant nutrition. Dordrecht: Springer, 2001. 849p. DOI: https://doi.org/10.1007/978-94-010-1009-2

MÓGOR, A. F.; CÂMARA, F. L. A. Teores de fósforo, potássio e produção de alface orgânica em diferentes coberturas do solo. Bioscience Journal, Uberlândia, v. 25, n. 3, p. 112-118, 2009.

OLIVEIRA, N. L.; PUIATTI, M.; SANTOS, R. H. S.; CECON, P. R.; BHERING, A. S. Efeito da urina de vaca no estado nutricional da alface. Revista Ceres, Viçosa, v. 57, n. 4, p. 506-515, 2010.

PEDRINHO, D. R.; BONO, J. A. M.; LUDWIG, J.; MARTINEZ, V. R.; FARIA, M. R. Cultivation of lettuce fertilized with controlled release nitrogen fertilizer and urea. Bioscience Journal, Uberlândia, v. 31, n. 4, p. $997-$ 1003, 2015. https://doi.org/10.14393/BJ-v31n4a201526122

PEREIRA, C. M. S.; ANTUNES, L. F. S.; AQUINO, A. M.; LEAL, M. A. A. Substrato à base de esterco de coelho na produção de mudas de alface. Nativa, Sinop, v. 8 , n. 1, p. 58-65, 2020.2 DOI: http://dx.doi.org/10.31413/nativa.v8i1.8018
PETRIKOSKI, A. P.; BORGES, R.; MARQUES, P. T.; FUKAMACHI, C. R. B. Estudos preliminares do desenvolvimento de um fertilizante de liberação lenta de nitrogênio recoberto a partir de fonte biodegradável de polímero. Synergismus Scyentifica, Pato Branco, v. 6, n. 1, p. 1-7, 2011.

RESENDE, G. M.; ALVARENGA, M. A. R.; YURI, J. E.; SOUZA, R. J. Rendimento e teores de macronutrientes em alface americana em função de doses de nitrogênio e molibdênio. Horticultura Brasileira, Brasília, v. 30, n. 3, p. 373-378, 2012. DOI: https://doi.org/10.1590/S010205362012000300003

SANTANA, C. T. C.; SANTI, A.; DALLACORT, R.; SANTOS, M. L.; MENEZES, C. B. Desempenho de cultivares de alface americana em resposta a diferentes doses de torta de filtro. Revista Ciência Agronômica, Fortaleza, v. 43, n. 1, p. 22-29. 2012.

SANTOS, B. R.; BACALHAU, F. B.; PEREIRA, T. S.; SOUZA, C. F.; FAEZ, R. Chitosan-Montmorillonite microspheres: A sustainable fertilizer delivery system. Carbohydrate Polymers, v. 127, p. 340-346, 2015. DOI: https://doi.org/10.1016/j.carbpol.2015.03.064

SARKAR, A.; BISWAS, D. R.; DATTA, S. C.; ROY, T.; BISWAS, S. S.; GHOSH, A.; SAHA, M.; MOHARANA, P. C.; BHATTACHARYYA, R. Synthesis of poly (vinyl alcohol) and liquid paraffin-based controlled release nitrogen phosphorus formulations for improving phosphorus use efficiency in wheat. Journal of Soil Science and Plant Nutrition, p. 1-15, 2020. https://doi.org/10.1007/s42729-020-00249-3

SILVA, A. A.; SILVA, T. S.; VASCONCELOS, A. C. P.; LANA, R. M. Q. Aplicação de diferentes fontes de ureia de liberação gradual na cultura do milho. Bioscience Journal, v. 28, n. 1, p. 104-111, 2012.

SILVA, P. C. R.; PAIVA, P. E. B.; CHARLO, H. C. O.; COELHO, V. P. M. Slow release fertilizers or fertigation for sugarcane and passion fruit seedlings? Agronomic performance and costs. Journal of Soil Science and Plant Nutrition, 2020. https://doi.org/10.1007/s42729-020-00285-z

SILVEIRA, A. J.; FINZI, R. R.; CABRAL NETO, L. D.; MACIEL, G. M.; BELOTI, I. F.; JACINTO, A. C. P. Genetic dissimilarity between lettuce genotypes with different levels of carotenoids biofortification. Nativa, Sinop, v. 7, n. 6, p. 656-660, 2019. DOI: http://dx.doi.org/10.31413/nativa.v7i6.7331

TAIZ L., ZEIGER E. Fisiologia Vegetal. $6^{\mathrm{a}}$ ed. Porto Alegre: Artmed, 2017. 888 p.

TRANI, P. E.; RAIJ, B. Hortaliças. In: RAIJ, B. Recomendações de adubação e calagem para o estado de São Paulo - Boletim Técnico n. 100. 2 ed. Campinas: IAC, 1996. p.157-186.

VALERIANO, T. T. B.; SANTANA, M. J.; JESUS M. V.; LEITE, L. S. Manejo de irrigação para a alface americana cultivada em ambiente protegido. Nativa, Sinop, v. 6, n. 2, p. 118-123, 2018. DOI: http://dx.doi.org/10.31413/nativa.v6i2.5024 